AJKD

In the literature

\title{
Remote Ischemic Preconditioning: Would you give your right to arm to protect your kidneys?
}

(Commentary on Zarbock A, Schmidt C, Van Aken $\mathrm{H}$ et al: Effect of remote ischemic preconditioning on kidney injury among high-risk patients undergoing cardiac surgery: a randomized clinical trial. (1538-3598 (Electronic)).)

$$
\begin{aligned}
& \text { Heerajnarain Bulluck MD }{ }^{1,2} \text {, Luciano Candilio MD (Res) }{ }^{1,2} \text {, Derek J } \\
& \text { Hausenloy MD PhD }
\end{aligned}
$$

${ }^{1}$ The Hatter Cardiovascular Institute, University College London, London, UK

${ }^{2}$ The National Institute of Health Research University College London

Hospitals Biomedical Research Centre, London W1T 7DN, UK

${ }^{3}$ National Heart Research Institute Singapore, National Heart Centre Singapore

${ }^{4}$ Cardiovascular and Metabolic Disorders Program, Duke-National University of Singapore

\section{Corresponding author:}

Professor Derek Hausenloy

Cardiovascular and Metabolic Disorders Program,

Duke-National University of Singapore,

8 College Road

Singapore 169857,

Tel +65 66015121/65166719

Email derek.hausenloy@duke-nus.edu.sg

Disclosures: None to declare

Word Count: 1152

Keywords: Remote ischemic preconditioning, cardiac surgery, acute kidney injury, renoprotection 
The incidence of acute kidney injury (AKI) following cardiac bypass surgery can be as high as $30 \%^{1}$ and even a rise in serum creatinine smaller than the criterion for $\mathrm{AKI}$ after cardiac surgery is associated with an increased postsurgical morbidity and mortality ${ }^{2}$. While the etiology of AKI following surgery is multi-factorial and the precise underlying mechanisms remain unclear, acute tubular injury is the predominant pathology in severe cases of AKI. Although numerous strategies have been investigated to minimize AKI during cardiac surgery, there is currently no effective renoprotective intervention in clinical use $^{3}$.

In this context, remote ischemic preconditioning (RIPC), which refers to the phenomenon whereby transient non-lethal episodes of ischemia and reperfusion to a remote organ or tissue confer multi-organ protection against a sustained episode of ischemia/reperfusion to an organ of interest, may hold promise ${ }^{4,5}$. The results of studies investigating the potential for RIPC, performed using transient limb ischemia and reperfusion, to reduce the incidence of $\mathrm{AKI}$ following cardiac surgery have been inconsistent. It is therefore not surprising that the recently published study titled "Effect of remote ischemic preconditioning on kidney injury among high-risk patients undergoing cardiac surgery: a randomized clinical trial" by Zarbock et al ${ }^{6}$ in the Journal of American Medical Association has attracted significant attention.

\section{WHAT DOES THIS IMPORTANT STUDY SHOW?}

This multi-center study by Zarbock et $\mathrm{al}^{6}$ investigated the effect of RIPC on AKI in 240 patients undergoing on-pump cardiac bypass surgery. Only patients with chronic kidney disease at high-risk of developing AKI (as defined 
by a Cleveland Clinical Foundation score $^{7}$ of $\geq 6$ ) were eligible. The RIPC protocol comprised of 3 cycles of 5-minute upper arm cuff inflations/deflations. The study primary endpoint was the incidence of AKI as defined by the Kidney Disease: Improving Global Outcomes (KDIGO) criteria ${ }^{8}$ within the first 72 hours. Secondary endpoints included renal replacement therapy (RRT), myocardial infarction (MI), stroke, in-hospital and 30-day mortality; duration of intensive care unit and hospital courses; and changes in kidney injury biomarkers.

Participants randomized to receive RIPC prior to cardiac surgery experienced a $15 \%$ absolute risk reduction in the incidence of $\mathrm{AKI}$ when compared to the non-RIPC sham control. Among secondary endpoints, RIPC was associated with a 10\% absolute risk reduction in RRT and lower levels of AKI biomarkers (Neutrophil Gelatinase-Associated Lipocalin [NGAL] and Tissue Inhibitor of MetalloProteinases-2 [TIMP-2] and Insulin-Like Growth Factor Binding Protein 7 [IGFBP7]), although there were no differences in the incidence of $\mathrm{MI}$, stroke or mortality at 30 days. Finally, although RIPC reduced the duration of intensive care unit stay, there was no difference in the overall length of hospital stay.

There are several strengths to the study: (1) this was a multi-center study which only included patients at high-risk of AKI (as reflected by a high incidence of $\mathrm{AKI}$ of $52.5 \%$ in the control arm); (2) patients were administered volatile anesthesia instead of propofol, given the potential confounding effects of the latter on RIPC cardioprotection in the setting of cardiac surgery ${ }^{9,10}$; and (3) investigators attempted to maintain blinding of the treatment allocation by using a low cuff inflation sham RIPC protocol. 
Despite its numerous strengths, there are several minor limitations. Firstly, despite using the $\mathrm{KDIGO}$ criteria to grade $A \mathrm{KI}^{8}$, Zarbock et $\mathrm{al}^{6}$ used a cut-off of 72 hours to include patients with an increase in serum creatinine by $\geq 0.3 \mathrm{mg} / \mathrm{dl}$ from baseline rather than 48 hours as specified by the guideline ${ }^{8}$. Secondly, they did not report on the pre-existing use or intra-operative use of nitrates ${ }^{11}$ in each group, an agent which may have the potential to interfere with RIPC cardioprotection during cardiac surgery ${ }^{12}$. Finally, although the incidence of AKI was very high in the control arm, the follow-up time for major clinical endpoints was relatively short, and a longer duration of follow-up may have been more informative.

\section{HOW DOES THIS STUDY COMPARE WITH PRIOR STUDIES?}

Despite intensive investigation the actual mechanisms underlying organ protection elicited by $\operatorname{limb}$ RIPC remain unclear ${ }^{4,5,13}$. The current paradigm suggests that a blood-borne transferrable protective factor(s) is released in response to the limb RIPC stimulus ${ }^{5}$. The identity of the factor(s) remains unknown, although it is believed to be a peptide of less than 30 KiloDaltons in size - its release into the blood stream is dependent on an intact neural pathway to the RIPC-treated limb 5,14 .

The first study to investigate the effect of RIPC on the incidence of AKI following cardiac surgery was by Venugopal et al ${ }^{15}$ in 2010 , which reported a lower incidence of $\mathrm{AKI}$ in patients undergoing $\mathrm{CABG} \pm$ valve surgery. However, subsequent studies investigating the potential renoprotective effects of RIPC in the setting of cardiac bypass surgery have produced mixed results (Table

1). A recent meta-analysis of these randomized clinical trials did show a 
benefit of RIPC on kidney outcomes following cardiac surgery, although the included studies used an array of different kidney outcomes ${ }^{16}$.

The positive trial by Zarbock et $\mathrm{al}^{6}$ of 240 patients is the largest study to prospectively investigate the effect of RIPC on the incidence of AKI in the setting of cardiac surgery, and it was sufficiently powered for this outcome; in contrast, many of the previous studies had fewer patients and kidney outcomes were not primary endpoints. Zarbock et $\mathrm{al}^{6}$ specifically selected patients with chronic kidney disease, a population that would be expected to be at highest risk of developing post-surgical $\mathrm{AKI}$, whereas other studies have not restricted the study population based on the level of pre-operative kidney function. In the study by Zarbock et $\mathrm{al}^{6}$, volatile anesthesia was used instead of the intravenous anesthetic, propofol. It has been suggested in one small 72 patient study that RIPC may not reduce peri-operative myocardial injury during cardiac surgery 9,10 in the presence of propofol. Whether the use of propofol is enough to explain the neutral results observed in some of the past studies investigating the effect of RIPC on AKI is not clear, given that there appears to be no obvious correlation between the use of propofol and the absence of RIPC-associated benefits in prior trials (Table 1).

Whether the benefits observed in some of the phase II studies can translate to an improvement in clinical outcome in larger studies remains to be tested. However, the long-awaited ERICCA trial ${ }^{17}$, announced at the latest American College of Cardiology Scientific Session, showed that RIPC did not improve one-year clinical outcomes (cardiovascular death, MI, revascularization and stroke) in a cohort of 1612 patients. Importantly, RIPC had no effect on the incidence of AKI during cardiac surgery (a secondary 
endpoint). The results of the RIPHeart trial, in which AKI was a component of the primary endpoint, are eagerly awaited ${ }^{18}$.

Interestingly, RIPC has been reported to confer renoprotection in several other clinical settings including major vascular surgery ${ }^{19,20}$, elective percutaneous coronary intervention for stable coronary artery disease ${ }^{21,22}$, primary PCI for ST-segment elevation myocardial infarction patients ${ }^{23,24}$, and kidney transplantation ${ }^{25}$, although again not all studies have been positive ${ }^{26,27}$.

\section{WHAT SHOULD CLINICIANS AND RESEARCHERS DO?}

Strategies to protect against AKI during cardiac surgery have remained elusive. RIPC may be a feasible and low-cost therapeutic intervention meeting this need that could potentially confer additional neuroprotective and cardioprotective benefits. To date, no significant adverse effects have been reported with RIPC, and the discomfort associated with cuff inflation is not an issue in anesthetized patients.

Currently, RIPC cannot be routinely recommended for kidney and heart protection during cardiac surgery as there is no evidence that it improves clinical outcome in this clinical setting. However, the study by Zarbock et al ${ }^{6}$ has set the scene for a large scale randomized controlled trial, which accounts for patient risk factors and the choice of anesthetic agent, to confirm if RIPC can reduce the incidence of $\mathrm{AKI}$ and assess whether RIPC can improve clinical outcomes in patients undergoing cardiac bypass surgery. 


\section{Acknowledgements}

DJH is supported by the Rosetrees Trust, the National Institute for Health

Research University College London Hospitals Biomedical Research Centre and a BHF Senior Clinical Research Fellowship (FS/10/039/28270). 


\section{REFERENCES}

1. Thiele RH, Isbell JM, Rosner MH. AKI associated with cardiac surgery. Clinical journal of the American Society of Nephrology : CJASN. 2015;10(3):500-514.

2. Hobson CE, Yavas S, Segal MS, et al. Acute kidney injury is associated with increased long-term mortality after cardiothoracic surgery. (1524-4539 (Electronic)).

3. Landoni G, Bove T, Szekely A, et al. Reducing mortality in acute kidney injury patients: systematic review and international web-based survey. Journal of cardiothoracic and vascular anesthesia. 2013;27(6):1384-1398.

4. Hausenloy DJ, Yellon DM. Remote ischaemic preconditioning: underlying mechanisms and clinical application. Cardiovascular research. 2008;79(3):377-386.

5. Sivaraman V, Pickard JM, Hausenloy DJ. Remote ischaemic conditioning: cardiac protection from afar. Anaesthesia. 2015;70(6):732-748.

6. Zarbock A, Schmidt C, Van Aken H, et al. Effect of remote ischemic preconditioning on kidney injury among high-risk patients undergoing cardiac surgery: a randomized clinical trial. (1538-3598 (Electronic)).

7. Thakar CV, Arrigain S, Worley S, Yared JP, Paganini EP. A clinical score to predict acute renal failure after cardiac surgery. Journal of the American Society of Nephrology : JASN. 2005;16(1):162-168.

8. Group KA. KDIGO clinical practice guideline for acute kidney injury. Kidney Int. 2012;Suppl.(2):1-138.

9. Kottenberg E, Thielmann M, Bergmann L, et al. Protection by remote ischemic preconditioning during coronary artery bypass graft surgery with isoflurane but not propofol - a clinical trial. Acta anaesthesiologica Scandinavica. 2012;56(1):30-38.

10. Kottenberg E, Musiolik J, Thielmann M, Jakob H, Peters J, Heusch G. Interference of propofol with signal transducer and activator of transcription 5 activation and cardioprotection by remote ischemic preconditioning during coronary artery bypass grafting. The Journal of thoracic and cardiovascular surgery. 2014;147(1):376-382.

11. Gori T, Di Stolfo G, Sicuro S, et al. Nitroglycerin protects the endothelium from ischaemia and reperfusion: human mechanistic insight. British journal of clinical pharmacology. 2007;64(2):145-150.

12. Candilio L, Malik A, Ariti C, et al. Effect of remote ischaemic preconditioning on clinical outcomes in patients undergoing cardiac bypass surgery: a randomised controlled clinical trial. Heart. 2014.

13. Heusch G, Botker HE, Przyklenk K, Redington A, Yellon D. Remote ischemic conditioning. Journal of the American College of Cardiology. 2015;65(2):177-195.

14. Pickard JM, Botker HE, Crimi G, et al. Remote ischemic conditioning: from experimental observation to clinical application: report from the 8th Biennial Hatter Cardiovascular Institute Workshop. Basic research in cardiology. 2015;110(1):453.

15. Venugopal V, Laing CM, Ludman A, Yellon DM, Hausenloy D. Effect of remote ischemic preconditioning on acute kidney injury in nondiabetic patients undergoing coronary artery bypass graft surgery: a secondary 
analysis of 2 small randomized trials. American journal of kidney diseases: the official journal of the National Kidney Foundation. 2010;56(6):10431049.

16. Yang Y, Lang XB, Zhang P, Lv R, Wang YF, Chen JH. Remote ischemic preconditioning for prevention of acute kidney injury: a meta-analysis of randomized controlled trials. American journal of kidney diseases : the official journal of the National Kidney Foundation. 2014;64(4):574-583.

17. Hausenloy DJ, Candilio L, Laing C, et al. Effect of remote ischemic preconditioning on clinical outcomes in patients undergoing coronary artery bypass graft surgery (ERICCA): rationale and study design of a multi-centre randomized double-blinded controlled clinical trial. Clinical research in cardiology : official journal of the German Cardiac Society. 2012;101(5):339-348.

18. Meybohm P, Zacharowski K, Cremer J, et al. Remote ischaemic preconditioning for heart surgery. The study design for a multi-center randomized double-blinded controlled clinical trial--the RIPHeart-Study. European heart journal. 2012;33(12):1423-1426.

19. Ali ZA, Callaghan CJ, Lim E, et al. Remote ischemic preconditioning reduces myocardial and renal injury after elective abdominal aortic aneurysm repair: a randomized controlled trial. Circulation. 2007;116(11 Suppl):198-105.

20. Walsh SR, Boyle JR, Tang TY, et al. Remote ischemic preconditioning for renal and cardiac protection during endovascular aneurysm repair: a randomized controlled trial. Journal of endovascular therapy : an official journal of the International Society of Endovascular Specialists. 2009;16(6):680-689.

21. Er F, Nia AM, Dopp H, et al. Ischemic preconditioning for prevention of contrast medium-induced nephropathy: randomized pilot RenPro Trial (Renal Protection Trial). Circulation. 2012;126(3):296-303.

22. Zuo B, Wang $\mathrm{F}$, Song $\mathrm{Z}$, Xu M, Wang G. Using Remote Ischemic Conditioning to Reduce Acute Kidney Injury in Patients Undergoing Percutaneous Coronary Intervention: A Meta-analysis. (1473-4877 (Electronic)).

23. Crimi G, Ferlini M, Gallo F, et al. Remote ischemic postconditioning as a strategy to reduce acute kidney injury during primary PCI: A post-hoc analysis of a randomized trial. International journal of cardiology. 2014.

24. Yamanaka T, Kawai Y, Miyoshi T, et al. Remote ischemic preconditioning reduces contrast-induced acute kidney injury in patients with STelevation myocardial infarction: a randomized controlled trial. International journal of cardiology. 2015;178:136-141.

25. MacAllister R, Clayton T, Knight R, et al. REmote preconditioning for Protection Against Ischaemia-Reperfusion in renal transplantation (REPAIR): a multicentre, multinational, double-blind, factorial designed randomised controlled trial. NIHR Journals Library. Southampton (UK)2015.

26. Murphy N, Vijayan A, Frohlich S, et al. Remote ischemic preconditioning does not affect the incidence of acute kidney injury after elective abdominal aortic aneurysm repair. (1532-8422 (Electronic)). 
27. Menting TP, Sterenborg TB, de Waal Y, et al. Remote Ischemic Preconditioning To Reduce Contrast-Induced Nephropathy: A Randomized Controlled Trial. European journal of vascular and endovascular surgery : the official journal of the European Society for Vascular Surgery. 2015.

28. Zimmerman RF, Ezeanuna PU, Kane JC, et al. Ischemic preconditioning at a remote site prevents acute kidney injury in patients following cardiac surgery. Kidney Int. 2011;80(8):861-867.

29. Choi YS, Shim JK, Kim JC, et al. Effect of remote ischemic preconditioning on renal dysfunction after complex valvular heart surgery: a randomized controlled trial. The Journal of thoracic and cardiovascular surgery. 2011;142(1):148-154.

30. Rahman IA, Mascaro JG, Steeds RP, et al. Remote ischemic preconditioning in human coronary artery bypass surgery: from promise to disappointment? Circulation. 2010;122(11 Suppl):S53-59.

31. Young PJ, Dalley P, Garden A, et al. A pilot study investigating the effects of remote ischemic preconditioning in high-risk cardiac surgery using a randomised controlled double-blind protocol. Basic research in cardiology. 2012;107(3):256.

32. Meybohm P, Renner J, Broch O, et al. Postoperative neurocognitive dysfunction in patients undergoing cardiac surgery after remote ischemic preconditioning: a double-blind randomized controlled pilot study. PloS one. 2013;8(5): 64743.

33. Gallagher SM, Jones DA, Kapur A, et al. Remote ischemic preconditioning has a neutral effect on the incidence of kidney injury after coronary artery bypass graft surgery. Kidney Int. 2015;87(2):473-481. 
Table 1 Major studies investigating renoprotective effect of RIPC during cardiac surgery

\begin{tabular}{|c|c|c|c|c|c|c|}
\hline Study & $\mathbf{N}$ & $\begin{array}{l}\text { Clinical } \\
\text { setting }\end{array}$ & RIPC protocol & Anesthesia & Result & Notes \\
\hline \multicolumn{7}{|l|}{ Positive studies } \\
\hline $\begin{array}{l}\text { Venugopal et al } \\
2010^{15}\end{array}$ & 78 & $\begin{array}{l}\text { Adult } \mathrm{CABG} \pm \\
\text { valve }\end{array}$ & Three-5 min arm I/R vs un-inflated cuff & $\begin{array}{l}60 \% \text { volatile/40\% } \\
\text { propofol }\end{array}$ & Reduction in AKI & $\begin{array}{l}\text { Diabetic patients excluded. } \\
\text { Secondary renal endpoint }\end{array}$ \\
\hline $\begin{array}{l}\text { Zimmermann et al } \\
2011^{28}\end{array}$ & 118 & $\begin{array}{l}\text { Adult } C A B G \pm \\
\text { valve }\end{array}$ & Three-5 min arm I/R vs no sham & $100 \%$ volatile only & Reduction in AKI & Primary renal endpoint \\
\hline $\begin{array}{l}\text { Candilio et al } \\
2015^{12}\end{array}$ & 178 & $\begin{array}{l}\text { Adult } C A B G \pm \\
\text { valve }\end{array}$ & $\begin{array}{l}\text { Two-5 min arm and leg l/R vs un-inflated } \\
\text { cuff }\end{array}$ & $\begin{array}{l}85 \% \text { both volatile } \\
\text { and propofol }\end{array}$ & $\begin{array}{l}\text { Reduction in AKI (borderline-significant } \\
\mathrm{P}=0.06 \text { ) }\end{array}$ & Secondary renal endpoint \\
\hline $\begin{array}{l}\text { Zarbock et al } \\
2015^{6}\end{array}$ & 240 & $\begin{array}{l}\text { Adult } \mathrm{CABG} \pm \\
\text { valve }\end{array}$ & $\begin{array}{l}\text { Three- } 5 \text { min arm I/R vs low inflation } \\
\text { pressure sham }\end{array}$ & $100 \%$ volatile only & $\begin{array}{l}\text { Reduction in renal biomarkers (NGAL } \\
\text { and TIMP-2 } \times \text { IGFBP7), AKI and need } \\
\text { for dialysis }\end{array}$ & Primary renal endpoint \\
\hline \multicolumn{7}{|l|}{ Neutral studies } \\
\hline Choi et al $2011^{29}$ & 76 & $\begin{array}{l}\text { Adult valve } \pm \\
\text { CABG }\end{array}$ & Three-10 min leg I/R vs un-inflated cuff & $100 \%$ volatile & $\begin{array}{l}\text { No difference in renal biomarkers } \\
\text { (cystatin } \mathrm{C} \text { and NGAL) or AKI }\end{array}$ & Primary renal endpoint \\
\hline $\begin{array}{l}\text { Rahman et al } \\
2011^{30}\end{array}$ & 162 & $\begin{array}{l}\text { Adult CABG } \\
\text { only }\end{array}$ & $\begin{array}{l}\text { Three- } 5 \text { min arm I/R vs proper sham RIPC } \\
\text { protocol }\end{array}$ & $98 \%$ volatile & $\begin{array}{l}\text { No difference in serum } \mathrm{Cr} \text { at } 4 \text { days or } \\
\text { dialysis }\end{array}$ & Secondary renal endpoint \\
\hline $\begin{array}{l}\text { Young et al } \\
2012^{31}\end{array}$ & 96 & $\begin{array}{l}\text { Adult CABG } \pm \\
\text { valve }\end{array}$ & $\begin{array}{l}\text { Three- } 5 \text { min arm l/R vs proper sham RIPC } \\
\text { protocol }\end{array}$ & $\begin{array}{l}\text { Both volatile and } \\
\text { propofol }\end{array}$ & No difference in AKI & Secondary renal endpoint \\
\hline $\begin{array}{l}\text { Meybohm et al } \\
2014^{32}\end{array}$ & 180 & $\begin{array}{l}\text { Adult } \mathrm{CABG} \pm \\
\text { valve }\end{array}$ & $\begin{array}{l}\text { Four-5 min arm I/R vs proper sham RIPC } \\
\text { protocol }\end{array}$ & $100 \%$ propofol & No difference in AKI & Secondary renal endpoint \\
\hline $\begin{array}{l}\text { Gallagher et al } \\
2014^{33}\end{array}$ & 86 & $\begin{array}{l}\text { Adult } C A B G \pm \\
\text { valve }\end{array}$ & Three-5 min arm I/R vs un-inflated cuff & $\begin{array}{l}87 \% \text { volatile } / 13 \% \\
\text { ICCF }\end{array}$ & $\begin{array}{l}\text { No difference in serum } \mathrm{Cr} \text { at } 4 \text { days or } \\
\text { dialysis }\end{array}$ & $\begin{array}{l}\text { Selected CKD patients with } \\
\text { low eGFR }(<60) \\
\text { Primary renal endpoint }\end{array}$ \\
\hline
\end{tabular}

$\mathrm{I} / \mathrm{R}=$ Ischemia/Reperfusion; $\mathrm{AKI}=$ acute kidney injury; $\mathrm{CABG}=$ coronary artery bypass graft; $\mathrm{Cr}=$ creatinine; eGFR=estimated glomerular filtration rate;

$\mathrm{ICCF}=$ Intermittent cross-clamp fibrillation; $\mathrm{RIPC}=$ remote ischemic preconditioning; $\mathrm{CKD}=$ chronic kidney disease 